\title{
Optimization of Important Factors on the Adsorption of Methyl Violet by Modified Palm Fiber Using Experimental Design Method
}

\author{
Maryam Abrishamkar $^{a, b}$, Rashin Andayesha, ${ }^{a, b}, *$ Hossein Hodaee Hab $^{a, b}$ \\ a Department of Chemistry, Science and research Branch, Islamic Azad University, Ahvaz, Iran \\ ${ }^{b}$ Department of Chemistry, Islamic Azad University of Ahvaz, Ahvaz, Iran
}

\section{A R T I C L E I N F O}

Received: 2 August 2019

Revised: 28 August 2019

Accepted: 29 August 2019

Available online: 30 August 2019

\section{K E Y W O R D S}

Cloud point extraction Propylene oxide-ethylene oxide block polymer APDC

\begin{abstract}
A B S T R A C T
Via Box-Behnken method, we evaluated the influence of various factors on adsorption, including the amount of adsorbent, the speed of stirring the solution and adsorbent, $\mathrm{pH}$ of solution, time of contact, and various concentrations of violet methyl colour, to obtain optimum conditions. The maximum extent of violet methyl removal was found at $100 \mathrm{mg} / \mathrm{L}$ concentration, $\mathrm{pH}=4.6$, contact time $=50$ minutes, 120 rotation speed, and adsorbent dose $=1.488 \mathrm{~g} / \mathrm{L}(0.0744$ gram in 50 millilitre). In order to determine the reaction mechanism, two kinetic models were used, namely pseudo-first-order and pseudo-second kinetics models. The adsorption kinetics followed pseudo-second order model, and the mechanism of chemical reaction was the rate-limiting step. Furthermore, the Langmuir and Freundlich Isotherms were considered for adsorbing the violet methyl on the palm fiber adsorbent. The adsorption isotherms showed a balanced relationship between the materials adsorbed on the adsorbent $\left(\mathrm{q}_{\mathrm{e}}\right)$ and a balanced concentration in the solution $\left(\mathrm{C}_{\mathrm{e}}\right)$ at a constant temperature. This method was used to remove the violet methyl colour from real samples such as industrial sewage, tap and river water.
\end{abstract}

G R A P H I C A L A B S T R A C T

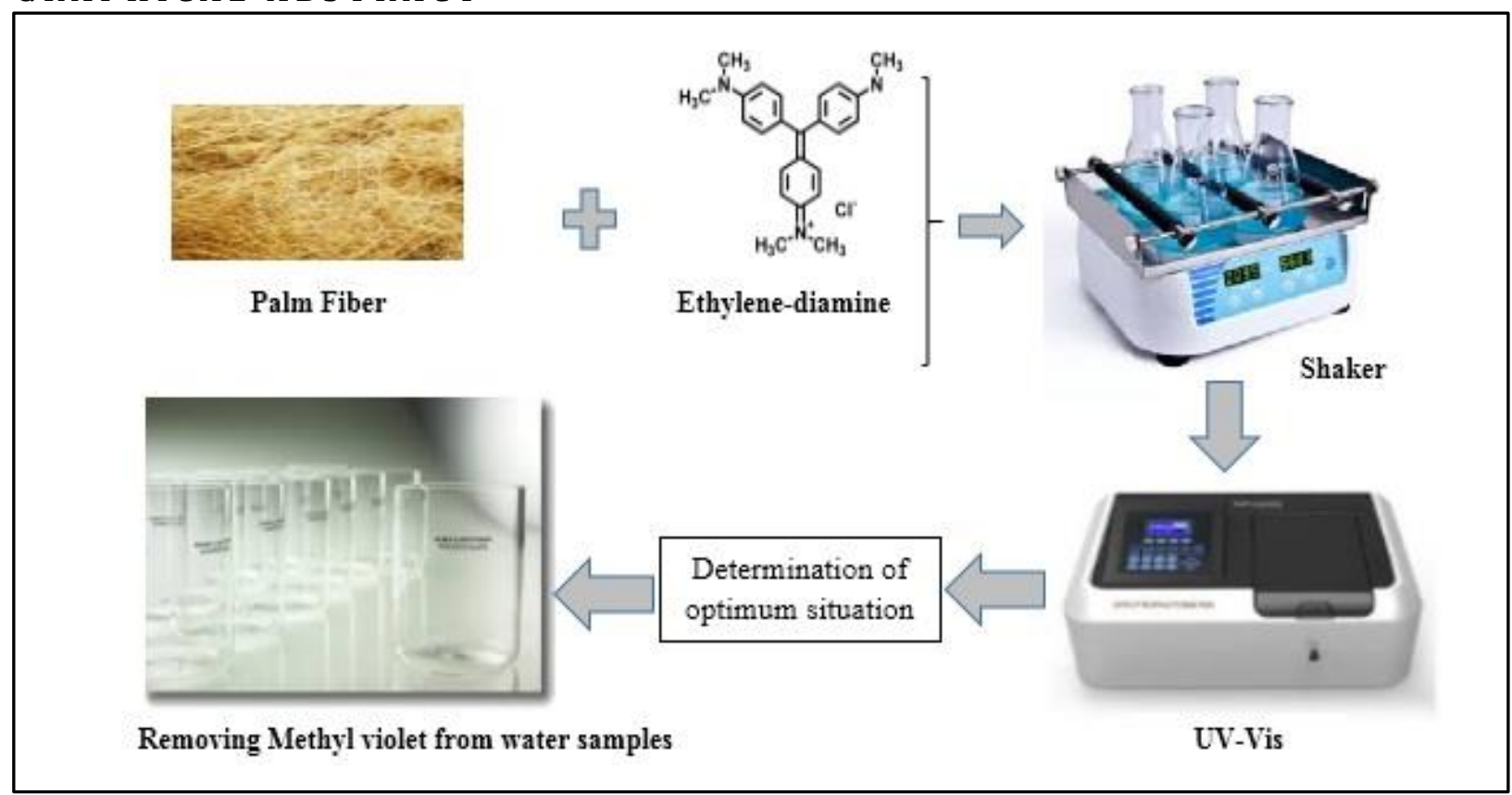

* Corresponding author's E-mail address: rashinandayesh@gmail.com 


\section{Introduction}

Chemical dyes constitute a large part of organic compounds with hydrophilic and hydrophobic linkage; the chemical dyes are polluted in natural waters which has been employed in industrial and domestic uses. Curriers, forgers, and manufacturers of plastic, food and cosmetics are among industries that extensively use colours. Effluents of industries are pollutants and among all these industries, textile industry has the highest rate of dye use for colouring a variety of different fibres [1-4]. The use of dyes increases because of industrial development and growing demand of colour fabrics. Today, about ten thousand dyes and pigments are used in various textile industries, amounting to an annual global production of around $7 \times 10^{5} \mathrm{~T}$, about 50 percent of which are Azodyes [5]. It is estimated that about 5-10 percent of chromogenic materials that enter streams and waters are disposed by the textile industry [6]. Not only do dyes give the water an undesirable colour, but they are also harmful compounds which can produce toxins via oxidation, hydrolysis or other chemical reactions that occur in water. Aromatic colours, in particular, contain carcinogen which is based on benzidine and aryl amines. In fact, some of the mutations which occur are because of harmful chemicals such as benzidine, metals and so forth. For this reason, it is necessary to remove the synthetic organic dyes from wastewater of factories. A wide range of studies have been conducted by chemical, biological and biochemical processes in order to remove the pollution produced by the textile industry. Some other processes used to remove heavy metals and dyes from waste water contaminated with dyes include adsorption [7], coagulation or flocculation [8,9], chemical oxidation [10], and membrane filtration [11]. Methyl violet is a heterocyclic aromatic compound with molecular formula $\mathrm{C}_{24} \mathrm{H}_{28} \mathrm{~N}_{3} \mathrm{Cl}$. At room temperature, this compound is a dark green powder which is odorless, solid and soluble in water, ethanol and diethylene glycol. Methyl violet is used as an indicator and a chemical reagent in analytical chemistry and can be seen purple in an alkaline solution and yellow in an acid solution. Methyl violet removal as an alkaline dye from the aqueous solution has been investigated during the photo catalytic reaction and Sono photo catalytic by nanoparticles of titanium dioxide. The effect of different parameters on the elimination of methyl violet has been studied, including the concentration of nano-catalyst, the initial concentration of dye, power of UV radiation, temperature and time contact. Research has further shown that higher temperatures and lower initial concentrations result in higher removal rates. Methyl violet is used as a model for evaluating the adsorption capacity of different adsorbents. Preparing biological industrial wastewater includes biodegradable methods, such as De-fungal paint, Microbial degradation and uptake by microbial biomass [12,13]. However, the use of this method is often limited because of technical problems. Moreover, although many organic molecules break, many others do not, owing to their complex chemical structures and synthetic organic origins [14]. Adsorption is the result of the interaction between physical attraction forces between porous solid surfaces and substance molecules taken from the fluid phase and it is caused by accumulation of concentration on the surface, contrary to absorption which is the result of accumulation of concentration in gas or liquid phase. Requiring less surface (almost oneeighth the level required in biological systems), less sensitivity to daily changes, ineffectiveness of toxic chemicals, greater flexibility in design and function, and the ability to remove chemical pollutants, are some advantages of adsorption over other conventional treatment methods for wastewater treatment [15]. Many solids have 
the ability to attract the amount of gas or mass dissolved in the solvent. Adsorbents should have a high internal volume, and be accessible to detachable components of the fluid. Adsorbents must also have good mechanical properties such as power resistance to attrition, and the kinetic properties (reactivity) are to be acceptable; for instance, the transfer capability of adsorbed molecules to the active points of adsorption should be high. Parameters effective on adsorption are adsorbent surface, contact time, the solubility of solutes in the fluid (wastewater), sorbent particle size and the size of molecule with due attention to pore size [16]. Silica gel, activated carbon, resins and carbonized polymers, absorbent polymers, clay, zeolites and firewood are adsorbents among which, activated carbon is widely used thanks to its high specific surface and porous structure; however, its use on a large scale is not costeffective because its reconstruction and repairs are costly and challenging [17]. Therefore, it is necessary to use adsorbents with the same high performance but economically cheaper. Examples of natural adsorbents are clay and clay minerals, cellulosic materials, ketins, metal hydroxide sludge, chrome sludge, corncob, bagasse pith, banana and orange peels. Colours are chemicals which can colour materials. Dyes are ionic or aromatic organic compounds with structures such as Ariely ring with delocalized electron systems. It is an indisputable fact that the colour of colour combinations is due to the absorption of light by one or more of the polyunsaturated connections. These connections or groups were named Chromophore in 1876 by Witt Groups; they do not own a colour material but increase the colour strength of a chromophore named Auxochrom. In the majority of cases, chromophore is a covalent unsaturated such as $-\mathrm{HSO}_{3},-\mathrm{COOR},-\mathrm{COOH},-\mathrm{N}=\mathrm{N}-,-\mathrm{C} \equiv \mathrm{C}-,-\mathrm{N}=\mathrm{O}-$, $-\mathrm{NO}_{2^{-}},-\mathrm{Br}$, and etc [18]. Activated carbon is one of the most popular materials for removing pollutants from wastewater, and is the oldest adsorbent which can be made from agricultural waste such as sawdust [19], coal, wood [20], lignite [21], and coconut [22], or from municipal and industrial wastes such as waste bottle, waste tires [23], and newspaper [24]; it is activated by chemical or physical approaches. Recently, the role of sawdust in the removal of contaminants from aqueous solutions has been investigated, and it has been proven that sawdust is the active ingredient for the removal of dyes from aquatic environments $[25,26]$. Ross, rich in polyphenols, is another waste product from the timber industry effective in the removal of dyes from aqueous solutions [27]. Palm fiber, an agricultural waste, is chemically inert, nontoxic and biodegradable. As a renewable source, this waste is abundant, always available, and can be used as an absorbent for the removal of dyes from aqueous solutions. By the increase in the amount of sorbent, uptake efficiency is increased but the density of absorption (absorption per unit mass) is reduced. Particle size reduction increases the surface, absorption time on the outer layer milled particles of palm fiber. The test temperature should be selected optimally to increase the absorption rate. Results have shown that the speed of agitation affects the absorption rate, and absorption, more often than not, increases by increasing the contact time. In 2008, Ofomaja studied the methyl violet and methylene blue adsorption from aqueous solutions using sawdust as an adsorbent. Different factors were tested and the optimum conditions were obtained where both dyes were isolated in $0.004 \mathrm{gL}^{-1}$ of the amount of adsorbent, $120 \mathrm{~m} / \mathrm{gL}^{-1}$ of initial dye concentration, $200 \mathrm{rpm}$ of stirring, $\mathrm{pH}=10$ and $0.225 \mu \mathrm{m}$ of particle size. The results showed that the dye adsorption on sawdust followed the pseudo-second-order kinetic model. The mechanism of this process includes both mass transfer and diffusion between the particles [28]. In 2008, Mittal and colleagues removed 
Methyl violet dye from aqueous solutions using agricultural waste (the remains of plants and De-oiled soya) as adsorbents [29]. In 2011, Chowdhury and co-workers studied the ability of palm fiber for removing $\mathrm{Cu}$ (II) from aqueous solutions [30]. Experiments were designed by changing parameters including $\mathrm{pH}$, the amount of adsorbent, contact time and initial concentration of metal ions. Equilibrium data of absorption was analyzed by Langmuir isotherm, Freundlich and Temkin where Langmuir isotherm offered the optimal correlation among the experimental data. It was further observed that adsorption kinetics followed the pseudosecond order kinetic model, and $\mathrm{Cu}$ (II) was isolated by $96.03 \%$ at $\mathrm{pH}=5.5$ and two-hour contact time. In 2010, Kathiresan et al. [31] studied palm fiber as an absorbent for methyl orange dye. In 2008, Isa et al. [32] investigated the removal of ammonia nitrogen on zeolite and palm fiber. The greatest uptake was obtained in the removal of ammonia nitrogen from aqueous solutions with $\mathrm{pH} 4.2$ and 3.7 regarding zeolite and palm fiber, respectively. In 2011, Daneshvar and co-workers attempted to remove Acid Black1 (AB1) by bio sorption on brown macro algae [33]. In 2011, Heshmatnezhad et al., attempted to remove $\mathrm{Pb}^{2+}$ by Micellar enhanced ultrafiltration (MEUF) [34]. They used Box Behnken model to optimize the exclusion criteria of $\mathrm{Pb}^{2+}$ including the concentration of Input SDS22, the proportion of SDS to $\mathrm{Pb}^{2+}$ and $\mathrm{pH}$ solution. Moradi and Azizian used methyl violet to study adsorption kinetics and isotherms, and determine nanostructured carbon covered sand [35]. In this study, the influence of various factors on adsorption, including the amount of adsorbent, the speed of stirring the solution and adsorbent, $\mathrm{pH}$ of solution, time of contact, and various concentrations of violet methyl colour was studied to determine the most effective factors on the amount of adsorption. Besides, experimental design method is used to investigate the effect of different parameters to determine which factors is effective solely or in contact with other parameters. Considering all effective factors, the total number of tests would be so much. Therefore, using experimental design method can lead to decreasing the time and costs of the process.

\section{Experimental}

\section{Reagent and solutions}

Hydrochloric Acid 37\%, Methyl violet dye and Sodium hydroxide were purchased from Merck Company. The double distilled water was prepared in laboratory. Palm fiber was used as an adsorbent in this study prepared from palm trees of Jannat Makan village in the suburbs of Gotvand Township.

\section{Preparing sorbent}

Palm fiber used in the present study was prepared from palm trees of Jannat Makan village (in the suburbs of Gotvand Township in Khuzestan province) in winter. Prior to be used as a sorbent, it was washed by detergent and drinking water in order to remove dust and mud, and then, it was rinsed by distilled water. After that, it was dried by the oven at $80^{\circ} \mathrm{C}$ for 24 hours. In order to obtain modified palm fiber, dried palm fiber was crushed by gristmill (at different times of grinding to make different estimated sizes). In order to obtain different particle sizes $(0.25,0.5,0.1$, $0.75 \mathrm{~mm}$ ), laboratory screening was used in various meshes $(0.2,0.5,0.7$ and $1.0 \mathrm{~mm})$ and different sizes were obtained. Therefore, in order to prepare modified palm fiber, $5 \mathrm{~g}$ of palm fiber was gradually added to $70 \mathrm{~mL}$ of concentrated hydrochloric acid in a $100 \mathrm{~mL}$ volumetric flask. After 2 hours, it was smoothed by thick filter paper to completely remove the excess acid. Then, ethylenediamine was added to a $30 \mathrm{~mL}$ volumetric flask and after 2 hours, the adsorbent was smooth and washed by distilled water to make the leachate clear and colourless. So, 
solid adsorbent on the filter paper was placed on aluminium foil in the oven at $80^{\circ} \mathrm{C}$ and was dried for 24 hours.

\section{Instrumentation}

We made use of two beam spectrophotometer Lambda135 model made by Perkin-Elmer manufacturers and $1 \mathrm{~cm}$ glass cells for measuring the absorption and drawing the whole colour solutions in $\lambda=581.6 \mathrm{~nm}$. To control the $\mathrm{pH}$ of aqueous solutions, $\mathrm{pH}$ meter $\mathrm{F}-11$ model made by Horiba in Japan was used. A HS 501 digital model shaker made by IKA-Werker in Germany was used for multiple stirring of the solution. A balance BP210D model with a weighing capacity of $200 \mathrm{~g}$ and accuracy of $0.0001 \mathrm{~g}$, by Sartaryus companies in Switzerland was made. Scanning electron microscope (SEM) model XL30 was made by Philips in Netherland. A centrifuge device made by Kokusan manufacturers in Japan was used.

\section{Static laboratory method}

In order to study the effect of important parameters, including $\mathrm{pH}$, the amount of adsorbent, the contact time, sorbent particle size, and stirring speed of solution, static tests were conducted at $25{ }^{\circ} \mathrm{C}$ to remove methyl violet dye. In this method, $50 \mathrm{~mL}$ of colour solution with a concentration of 100 and 200 ppm was added to a certain amount of palm fiber as an absorbent ( $0.1 \mathrm{~g})$; it was then stirred in the shakers at a constant speed of $120 \mathrm{rpm}$ for 50 minutes. Samples were centrifuged in a centrifuge for 15 minutes at different time intervals and the adsorption of the top layer of solution was measured by UVVis in $\lambda=581.6 \mathrm{~nm}$ to determine the residual concentration of methyl violet colour. The amount of adsorbed dye according $\mathrm{mg} / \mathrm{g}$ of sorbent and $\mathrm{q}_{\mathrm{e}}$ was obtained from Eq. (1), where $\mathrm{C}_{0}, \mathrm{C}_{\mathrm{e}}, \mathrm{V}, \mathrm{M}$ are the initial concentration of dye in the solution $(\mathrm{mg} / \mathrm{L})$, the balance concentration of dye $(\mathrm{mg} / \mathrm{L})$, the volume of the solution (L) and the amount of adsorbent (g), respectively. At all stages of the investigation, colour removal rate was obtained by Eq. (2).

$q e=\frac{(C 0-C e) V}{W}$

$\operatorname{Removal}(\%)=\left(\frac{\mathrm{C} 0 \_\mathrm{Ce}}{\mathrm{C} 0}\right) \times 100$

\section{The column method}

The column was studied because using the column of an adsorbent is more facile and convenient, requiring no stirring; furthermore, it is more efficient and more cost-effective in the industry. Accordingly, 0.1 $\mathrm{g}$ of modified palm fiber was placed at the bottom of column and $50 \mathrm{ml}$ of methyl violet dye solution was added. During 60 minutes, $50 \mathrm{~mL}$ of methyl violet dye was eluted. Then, the adsorbance of solution was measured, and it was observed that the outflow percentage of methyl violet colour is more than $90 \%$ when using the column.

\section{Results and discussion}

Studying the adsorption spectrum of methyl violet colour

To increase the sensitivity and selectivity of the method, the analyte must be measured at a wavelength with maximum adsorbance. To find the wavelength, the adsorption spectrum was drawn for methyl violet in an aqueous solution at a wavelength range of 300- $800 \mathrm{~nm}$, Figure 1. According to the obtained adsorption spectra, the maximum wavelength was $581.6 \mathrm{~nm}$ which was selected as the optimum wavelength. A calibration curve was obtained via measuring the concentration of methyl violet colour at a concentrations range of 0.10 to $10.00 \mathrm{ppm}$, measuring the absorbance at a maximum wavelength of $581.6 \mathrm{~nm}$, and using a spectrophotometer and glass vial (Figure 2). 
The line equation, $\mathrm{Y}=0.1212 \mathrm{X}+0.007$, is based on obtained adsorptions in which $\mathrm{X}$ is the concentration of methyl violet dye according to milligrams per litter. This calibration curve was used to determine the balance concentration of methyl violet colour and calculate the percentage of colour output.

Optimizing the parameters affecting the removal of methyl violet colour

In order to obtain the highest colour removal, effective parameters including the effect of $\mathrm{pH}$, adsorbent dosage, sorbent particle size, stirring rate, the contact time and initial dye concentration were studied in vitro, such that all parameters were kept constant and only one parameter was changed.

Studying the effect of solid particle size on colour removal

Figure 1. Adsorption spectrum of methyl violet colour

Figure 2. Calibration curve for measuring the concentration of methyl violet
Adsorption of cationic methyl violet dye on palm fiber was studied by varying the particle sizes of the test solution. To study the effect of particle size on the amount of adsorbed dye, $50 \mathrm{~mL}$ of colour solution with $100 \mathrm{mg} / \mathrm{L}$ of concentration were transferred to 4 Erlenmeyer flasks; after that, $1.0 \mathrm{~g}$ of adsorbent in various sizes was added to each flask and stirred on rotation speed $100 \mathrm{rpm}$ for 30 minutes.

The solution was cleared and the adsorption was read at a maximum wavelength of $581.6 \mathrm{~nm}$ by UV-Vis; the balance concentration of colour was obtained through standard curve. Figure 3 shows the effect of different sizes on the percentage of colour output, with an ultimate optimumoptimum particle size value of 0.25 $\mathrm{mm}$.
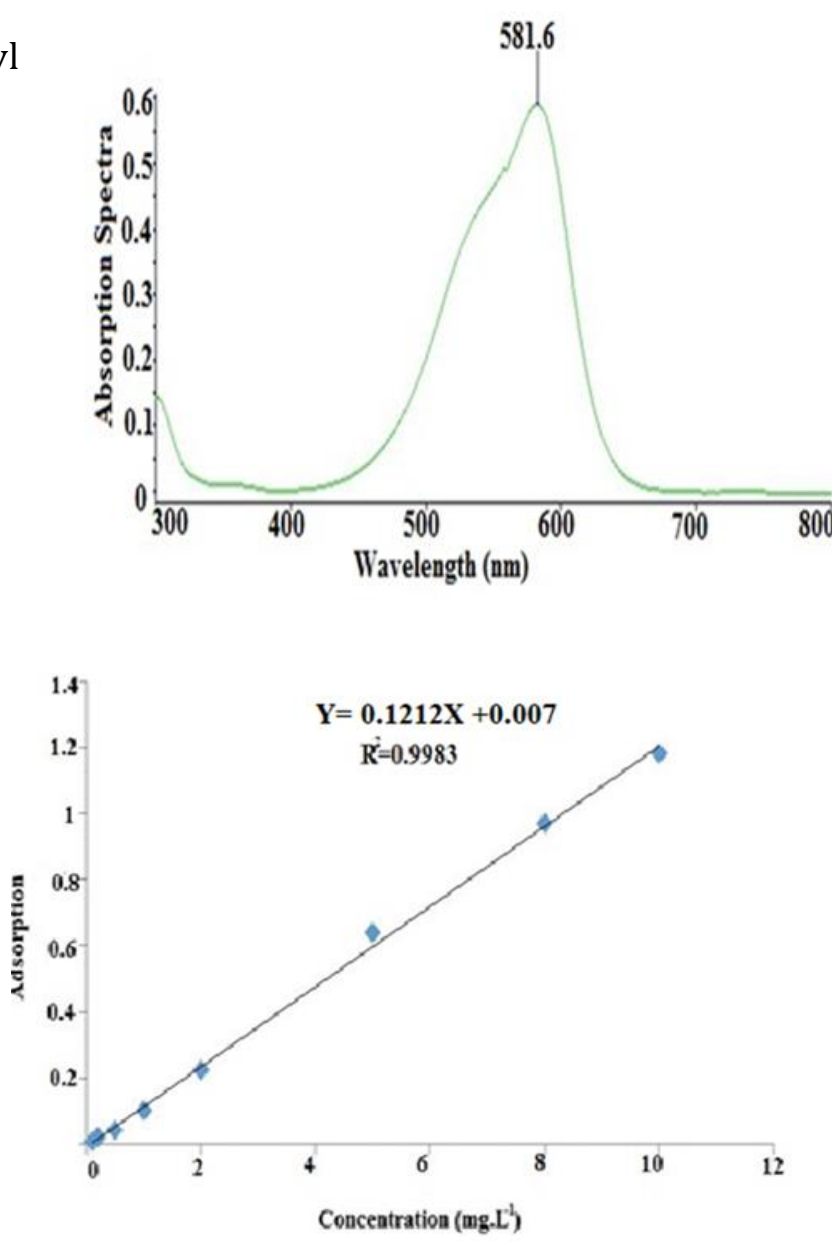
Figure 3. Percentage of methyl violet drain depending on size variation

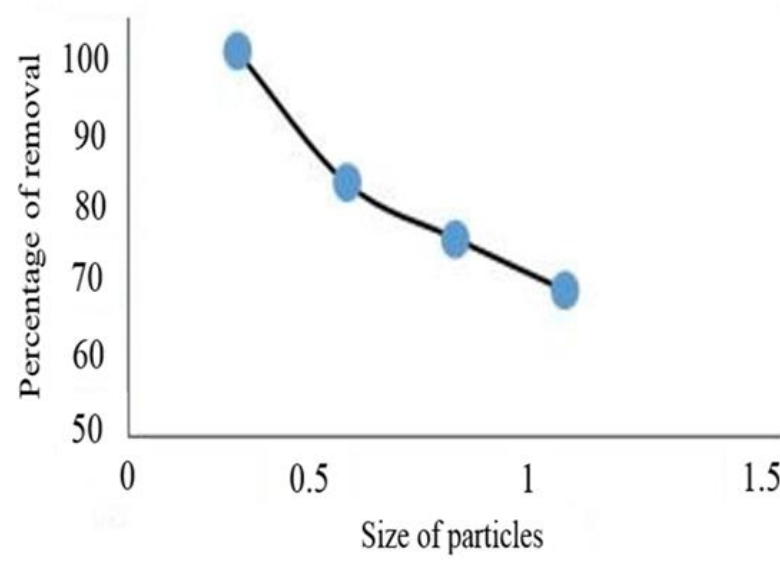

Figure 4 shows the effect of different factors on the removal of methyl violet colour when two factors were constant while other factors were variable. Adsorbent dosage and rotation speed were the most effective factors in the colour output by the modified adsorbent. Increasing the adsorbent dosage in the range of 0.5 to 2.0 gram per litter greatly increased the colour output, shown in Figure $4 \mathrm{a}, \mathrm{b}$ and c. In fact, with the increase in the adsorbent dosage and maintaining the volume of the solution, the contact surface between the adsorbent and solution, and the adsorption of colour have increased. By the increase in the adsorbent dosage, the colour output augmented even by changing the $\mathrm{pH}$ or rotation speed or contact time. Increasing the adsorbent dosage could increase the efficiency of colour output as shown in Figure 4b. It is obvious that when $\mathrm{pH}$ is equal to 9.5 and the contact time is 30 minutes and tests are done at 80-120 rotation speed, the best results will be achieved. Also, in Figure 4a, by increasing the adsorbent dosage, the percentage of colour output increases when the contact time is 30 minutes and the rotation speed are $100 \mathrm{rpm}$. Furthermore, increasing the adsorbent dosage can increase the colour output at different times when $\mathrm{pH}$ is 9 and rotation speed is set at $100 \mathrm{rpm}$, as it is shown in Figure 4c. According to Figure 4a$c$, increasing the adsorbent dosage can drastically augment the colour output, a trend which is curvature with a steep slope. 
Table 1. Designed experiments after using Box-Behnken method

\begin{tabular}{ccccccc} 
Run & $\begin{array}{c}\text { Adsorbent dosage } \\
\text { (g/L) }\end{array}$ & pH & $\begin{array}{c}\text { Time } \\
(\mathrm{min})\end{array}$ & $\begin{array}{c}\text { Rotation speed } \\
(\mathrm{rpm})\end{array}$ & $\begin{array}{c}\text { Practical } \\
\text { output } \\
\text { percent }\end{array}$ & $\begin{array}{c}\text { Output } \\
\text { percent } \\
\text { (predicted } \\
\text { by model) }\end{array}$ \\
1 & & & & & 62.33 & 61.05 \\
2 & 0.4 & 8.0 & 30 & 100 & 66.38 & 66.10 \\
3 & 0.4 & 11.0 & 30 & 100 & 92.96 & 94.17 \\
4 & 2.0 & 8.0 & 30 & 100 & 90.78 & 92.99 \\
5 & 2.0 & 11.0 & 30 & 100 & 71.16 & 73.43 \\
6 & 1.2 & 9.5 & 10 & 80 & 88.41 & 88.44 \\
7 & 1.2 & 9.5 & 50 & 80 & 80.86 & 81.76 \\
8 & 1.2 & 9.5 & 10 & 120 & 91.32 & 89.98 \\
9 & 1.2 & 9.5 & 50 & 120 & 87.25 & 85.29 \\
10 & 1.2 & 8.0 & 30 & 80 & 83.70 & 83.89 \\
11 & 1.2 & 11.0 & 30 & 80 & 87.00 & 86.89 \\
12 & 1.2 & 8.0 & 30 & 120 & 90.10 & 92.14 \\
13 & 1.2 & 11.0 & 30 & 120 & 57.59 & 56.68 \\
14 & 0.4 & 9.5 & 10 & 100 & 83.70 & 81.55 \\
15 & 2.0 & 9.5 & 10 & 100 & 60.93 & 63.16 \\
16 & 0.4 & 9.5 & 50 & 100 & 97.32 & 98.30 \\
17 & 2.0 & 9.5 & 50 & 100 & 72.61 & 74.13 \\
18 & 1.2 & 8.0 & 10 & 100 & 79.95 & 78.32 \\
19 & 1.2 & 11.0 & 10 & 100 & 87.38 & 88.00 \\
20 & 1.2 & 8.0 & 50 & 100 & 90.20 & 87.67 \\
21 & 1.2 & 11.0 & 50 & 100 & 59.86 & 60.22 \\
22 & 0.4 & 9.5 & 30 & 80 & 95.64 & 94.76 \\
23 & 2.0 & 9.5 & 30 & 80 & 69.80 & 69.68 \\
24 & 0.4 & 9.5 & 30 & 120 & 79.52 & 95.15 \\
25 & 2.0 & 9.5 & 30 & 120 & 79.01 & 79.00 \\
26 & 1.2 & 9.5 & 30 & 100 & 100 & 79.00 \\
27 & 1.2 & 9.5 & 30 & 100 & & \\
\hline & 1.2 & 9.5 & 30 & & & \\
\hline
\end{tabular}

Then, the effect of increasing $\mathrm{pH}$ in the range of 8 to 11 on the percentage of methyl violet colour output was studied. In Figure 4a, by increasing the $\mathrm{pH}$ to around 9.5, the efficiency of colour output is augmented and then reduced with 30 minutes of contact time and $100 \mathrm{rpm}$ of rotation speed and constant adsorbent doses. By increasing the $\mathrm{pH}$ to about 9.5, the efficiency of colour output, increases and then decreases when the adsorbent dose is 1.2 grams per litter and the constant time is 30 minutes in all rotation speed, Figure $4 \mathrm{~d}$. Also, by increasing the $\mathrm{pH}$ to around 9.5, over the span of 10 to 60 minutes, the colour output is increased and then slightly reduced, when the adsorbent dosage is 1.2 grams per litter and rotation speed is set at $100 \mathrm{rpm}$, Figure $4 \mathrm{e}$. Increasing the rotation speed in the range of 80 to $120 \mathrm{rpm}$ resulted in an increase in the colour output. By increasing the rotation speed, the efficiency of colour output curvy increases with a slight slope, at a $\mathrm{pH}$ of 9.5 , contact time of 30 minutes, and all adsorbent doses, Figure $4 \mathrm{~b}$. In Figure $4 \mathrm{e}$, by increasing the rotation speed, the percentage of colour output partially increases in all ranges of $\mathrm{pH}$, when the adsorbent dosage is 1.2 grams per litter and the contact time is set at 30 minutes. 


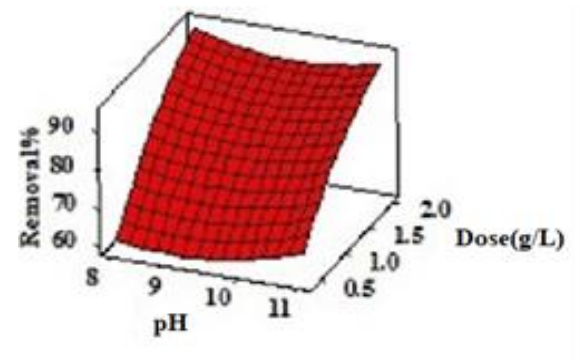

(a)

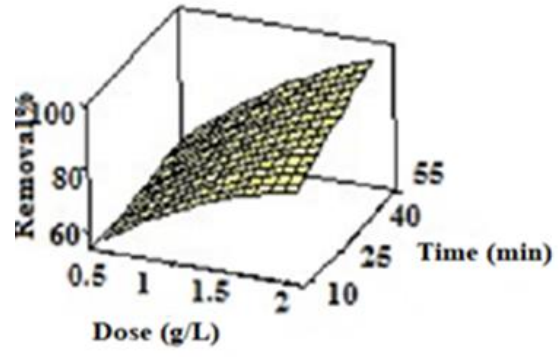

(c)

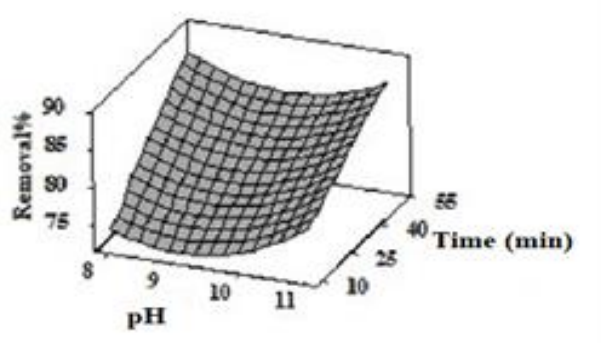

(e)

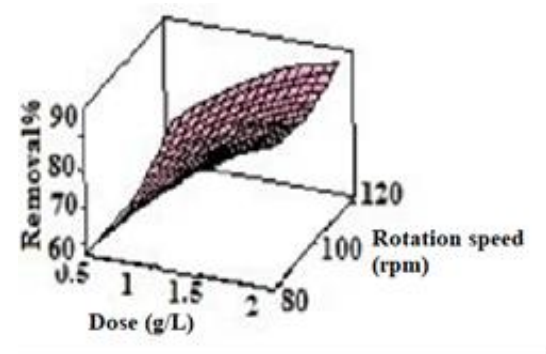

(b)

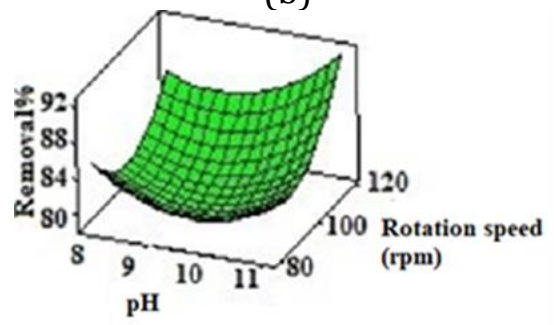

(d)

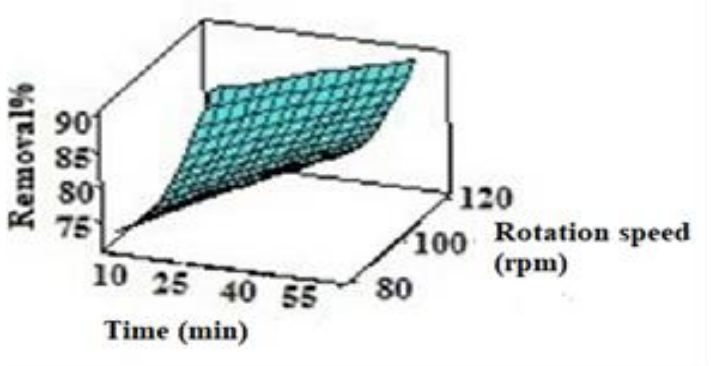

(f)

Figure 4. Comparing methyl violet removal changes with regards to: (a) adsorbent dose and $\mathrm{pH},(\mathrm{b})$ adsorbent dose and rotation speed, (c) adsorbent dose and contact time, (d) pH and rotation speed, (e) contact time and $\mathrm{pH}$, and (f) contact time and rotation speed

By augmenting the rotation speed, the percentage of colour output increases at all times in stationary conditions and when the adsorbent dosage is 1.2 gram per litter and $\mathrm{pH}$ is 9.5. In Figure $4 \mathrm{f}$, the increase in the percentage of colour output with the augment in rotation speed is quite evident, because the two factors affecting the colour output, namely the adsorbent dosage and $\mathrm{pH}$ were fixed; further investigated was the impact of changing the time and rotation speed on the colour output. The slight impact of time at 10 to 55 minutes on the colour output is obvious in Figure 4c, e and f. By increasing the time, the efficiency of colour output, as observed in Figure 4c, increases when $\mathrm{pH}$ is 9.5 and rotation speed is set at $100 \mathrm{rpm}$ for all tested doses. In Figure 4c, the increase in the efficiency of colour output is related to the slightly and linearly increasing slope of the contact time. In Figure 4e, by increasing the time, the percentage of colour output partially increases when the adsorbent dosage is $\mathbf{1 . 2}$ gram per litter and rotation speed is set at 100 rpm. Figure $4 \mathrm{f}$ shows that by increasing the time up to $50 \mathrm{~min}$, the percentage of colour output augments and is then reduced when the adsorbent dosage is 1.2 gram per litter and $\mathrm{pH}$ is set at 9.5. In this figure, the answer level of the two factors affecting the colour output, namely $\mathrm{pH}$ and the adsorbent dosage are considered, and the changes in the percentage of colour output is because of the rotation speed and contact time.

According to the interpretation of the answer level and data processing figures by 
ANOVA analysis of variance, the percentage of the colour output is specified in Table 2. The number of degrees of freedom (DF) was determined for each factor and squares and interactions in ANOVA table. According to data processing, a degree of freedom was given to each factor, squares and interactions. Considering the fact that the total degree of freedom is 26 , the residual was 12 . The sum of square (SS) and mean of square (MS) were obtained by dividing the sum of square by degrees of freedom. To determine $F$, the mean square of each agent is divided by the average remaining squares. Our software calculated $P$ with data processing. With a confidence level of $95 \%$, all factors with a P smaller than 0.05 had a significant impact on the efficiency of colour output. Factors affecting the efficiency of colour output of methyl violet based on Table 2 include: $\mathrm{pH}$, the adsorbent dosage, $\mathrm{pH}$ square and binary interaction between $\mathrm{pH}$ and adsorbent dosage. The optimal points for effective factors in colour output are shown in Table 3.

Table 2. Variance analysis for the percentage of methyl violet colour output

\begin{tabular}{cccccc} 
Source & DF & SS & MS & F & P \\
Regression & 14 & 3633.57 & 259.540 & 60.63 & 0.000 \\
Linear & 4 & & & & \\
Dose & 1 & 102.32 & 102.319 & 23.90 & 0.000 \\
pH & 1 & 55.41 & 55.406 & 12.94 & 0.051 \\
Time & 1 & 18.45 & 18.446 & 4.31 & 0.060 \\
Rotation speed & 1 & 80.86 & 80.861 & 18.89 & 0.001 \\
Square & 4 & & & & \\
Dose*Dose & 1 & 75.54 & 75.537 & 17.65 & 0.001 \\
pH*pH & 1 & 59.48 & 59.479 & 64.86 & 0.000 \\
Time*Time & 1 & 0.52 & 0.521 & 0.12 & 0.733 \\
Rotation speed* & 1 & 118.48 & 118.480 & 27.86 & 0.000 \\
Rotation speed & 6 & & & & \\
Interaction & 1 & 9.70 & 9.701 & 2.27 & 0.158 \\
Dose*pH & 1 & 26.38 & 26.380 & 6.16 & 0.029 \\
Dose*Time & 1 & 20.56 & 20.556 & 4.80 & 0.049 \\
Dose* Rotation & 1 & 5.11 & 5.111 & 1.19 & 0.296 \\
speed & 1 & 11.03 & 11.029 & 2.58 & 0.134 \\
pH*Time & 1 & & & & \\
pH* Rotation & 11.50 & 11.499 & 2.69 & 0.127 \\
speed & 12 & 51.37 & 4.281 & & \\
Time* Rotation & 1 & 49.90 & 4.990 & 6.77 & 0.135 \\
speed & 1.47 & 0.737 & & \\
Residual Error & 1 & & & & \\
Lack-of-Fit & 10 & & & & \\
Pure Error & 26 & 1 & & & \\
Total & & 1 & & & \\
\hline
\end{tabular}

\section{Studying the effect of $p H$}

The pH of colour solution plays an important role during the adsorption process, and particularly affects the adsorption capacity. This impact is related to the charge of the adsorbent surface, the degree of ionization of material into the solution, separation of the functional groups on the active sites of adsorbent and chemistry of colour solution. The effect of the $\mathrm{pH}$ of the solution on the amount of adsorbed dye was investigated by box-Behnken method. Due to the obtained possibility, $\mathrm{pH}$ is ineffective in colour removal. The results were analysed 
using one variable at a time. Therefore, the effect of changing the $\mathrm{pH}$ in the range of 2-10 and colour solution with an initial $\mathrm{pH}$ was investigated. For this purpose, $50 \mathrm{ml}$ of colour solution with $100 \mathrm{mg} / \mathrm{L}$ of concentration were added to 10 Erlenmeyer flasks; pH solution was adjusted by $\mathrm{NaOH}(99-100 \%)$ and $\mathrm{HCl}$ (37\%), and $1.488 \mathrm{gL}^{-1}$ of adsorbent size 0.25 was added to each Erlenmeyer flask, and stirred on the shaker for 50 minutes with 120 rpm. Then, the solution was cleared beside adsorbent and the adsorption was read at a maximum wavelength of $581.6 \mathrm{~nm}$, by UV-Vis; the balance concentration of colour was then calculated via the standard curve. According to Figure 5 , by increasing the $\mathrm{pH}$ from 2 to 3 , adsorption increases and then remains constant up to $\mathrm{pH} 10$. Thus, in order to avoid wasting the time and materials, the optimum $\mathrm{pH}$ was considered the $\mathrm{pH}$ of the dye solution.

\section{Studying the effect of the initial concentration}

In optimizing the various factors, the colour concentration was fixed at $100 \mathrm{ppm}$. In order to evaluate the percentage of dye removal at the same optimal conditions in other concentrations, concentrations between 100 to $400 \mathrm{mg}$ were studied. Thus, different amounts of 1000 gram per mL of dye solution were added to $50 \mathrm{ml}$ shushed balloons. After that, the solution was added to Erlenmeyer flasks containing $0.0744 \mathrm{~g}$ of adsorbent (the adsorbent dosage was 1.488 gram per litter) and stirred on the shaker for 50 minutes with $120 \mathrm{rpm}$. Then, the solution in contact with the adsorbent was cleared by paper filter and the solution remaining below the filter was maintained so as to determine the colour after the removal. The colour was poured into a glass cell and by use of a spectrophotometer, its adsorption was read at a wavelength of $581.6 \mathrm{~nm}$, and the concentration of the remaining colour was realized by a calibration curve; the percentage of colour output was further calculated. The results in Table 4 show that the optimum conditions for colour concentrations of up to $400 \mathrm{ppm}$ removed about $89 \%$ of the colour.

Table 3. Optimized properties for the removal of methyl violet dye

\begin{tabular}{cc}
$\mathrm{pH}$ & Solution of colour \\
Rotation speed & $120 \mathrm{rpm}$ \\
Contact time & $50 \mathrm{~min}$ \\
Adsorbent dose & $1.488 \mathrm{~g} / \mathrm{L}$ \\
Removal percent & 99.6 \\
\hline
\end{tabular}

Figure 5. Effect of $\mathrm{pH}$ on methyl violet removal percentage

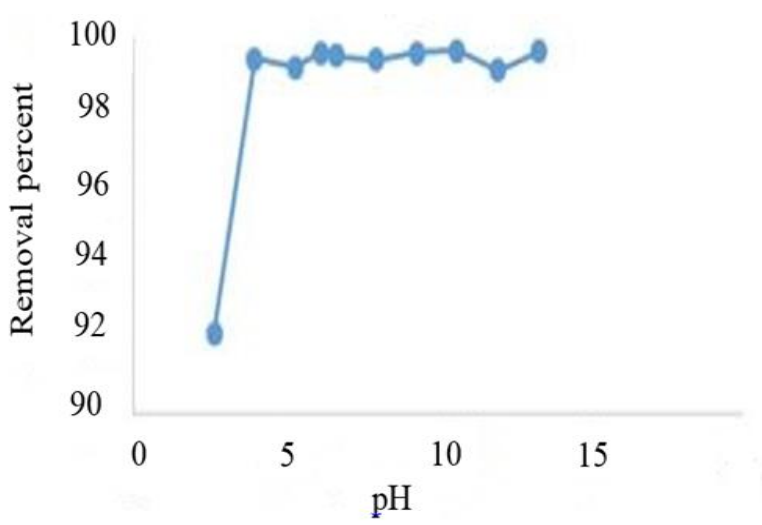


Table 4. Effect of ethylene-diamine on colour removal

\begin{tabular}{ccc} 
& $\begin{array}{c}\text { Colour removal (\%) } \\
\text { Modified sorbent by ethylene-diamine }\end{array}$ & Colour concentration $(\mathrm{mg} / \mathrm{L})$ \\
95.21 & 99.10 & 100 \\
75.70 & 96.81 & 200 \\
72.41 & 96.10 & 300 \\
49.52 & 89.00 & 400 \\
\hline
\end{tabular}

\section{Adsorption isotherms}

The adsorption isotherm indicates the time when the adsorption process reaches an equilibrium state, and also the distribution of adsorbed types between liquid and solid phases. In this study, the adsorption isotherms of Langmuir and Freundlich were used for investigating the adsorption behaviour of methyl violet colour solution on the modified palm fiber. These isotherms were used for initial concentrations in a range of $100-400 \mathrm{mg} / \mathrm{L}^{-1}$ in the previous optimum conditions. After calculating the remaining concentrations of the colour, the amount of $\mathrm{q}_{\mathrm{e}}$ was obtained according to Eq. (1), where the amount of adsorption colour per mass unit of adsorbent is in $\mathrm{mg} / \mathrm{g}^{-1} . \mathrm{C}_{0}\left(\mathrm{mg} / \mathrm{L}^{-1}\right), \mathrm{C}_{\mathrm{e}}\left(\mathrm{mg} / \mathrm{L}^{-}\right.$ ${ }^{1}$ ), $\mathrm{V}$ (L) and $\mathrm{W}$ (g) are the initial concentrations of adsorption, the equilibrium concentration of adsorption, the volume of the solution and the weight of sorbent, respectively.

\section{Langmuir isotherm}

Langmuir isotherm is used for adsorption on homogeneous surfaces with a slight interaction between adsorbed molecules. In order to study the adsorption of colour by modified palm fiber, based on Langmuir isotherm, Eq. (4) was used. $\left(1 / q_{e}\right)$ to $\left(1 / C_{e}\right)$ was drawn and results are shown in Table 5 and Figure 6. The amount of $\mathrm{R}^{2}=0.9545$ was further obtained for this isotherm. $\mathrm{C}_{e}\left(\mathrm{mg} / \mathrm{L}^{-}\right.$ $\left.{ }^{1}\right), \mathrm{q}_{\mathrm{e}}\left(\mathrm{mg} / \mathrm{g}^{-1}\right)$ and $\mathrm{q}_{\mathrm{m}}\left(\mathrm{mg} / \mathrm{g}^{-1}\right.$ of adsorbent) are the equilibrium concentration of adsorption, the amount of adsorbed colour per mass unit of adsorbent, and the highest amount of absorbed material, respectively.

$1 / \mathrm{q}_{\mathrm{e}}=1 / \mathrm{q}_{\mathrm{m}} / \mathrm{k}_{1} / \mathrm{C}_{\mathrm{e}}+1 / \mathrm{q}_{\mathrm{m}}$

These were obtained from the intercept and the slope of the equation in Figure 6 whose values are shown in Table 6. One of the basic characteristics of Langmuir isotherm and suitable adsorption can be expressed by a dimensionless factor called $\mathrm{R}_{\mathrm{L}}$ separation factor which is shown as Eq. (5), and its amount is shown in Table 6.

$\mathrm{R}_{\mathrm{L}}=1 /\left(\mathrm{k}_{1} / \mathrm{C}_{0}+1\right)$

$\mathrm{C}_{0} \quad\left(\mathrm{mgL}^{-1}\right)=$ the initial concentration of thiocyanate

$\mathrm{k}_{1}\left(\mathrm{Lmg}^{-1}\right)=$ the Langmuir constant

The amount of $\mathrm{R}_{\mathrm{L}}$ represents the isotherm type as it shows $\mathrm{R}_{\mathrm{L}}=0$, irreversible, $0<R_{L}<1$, suitable, $R_{L}=1$, liner and $R_{L}>1$, unsuitable. According to the obtained $\mathrm{R}_{\mathrm{L}}$ $\left(R_{L}=0.0099\right)$, the isotherm is favourable. Considering the amount of $\mathrm{R}^{2}$, methyl violet adsorption on palm fiber was acceptable and followed the Langmuir model.

\section{Freundlich isotherm}

Another important isotherm used in the study of adsorption is Freundlich isotherm which is an empirical model. This isotherm can be expressed by Eq. (6), in which $K_{f}$ is Freundlich constant which depends on the adsorption capacity of the adsorbent. To check this isotherm, the log of $\mathrm{q}_{\mathrm{e}}$ was plotted against the $\log$ of $\mathrm{C}_{\mathrm{e}}$, Table 7 . In Freundlich isotherm, if $1<\mathrm{n}<3$, the colour 
adsorption on the absorbent is highly desirable.

Table 5. Amounts of $1 / \mathrm{C}_{\mathrm{e}}, 1 / \mathrm{q}_{\mathrm{e}}$ in the colour of methyl violet for various primary concentration

\begin{tabular}{ccccc}
$\begin{array}{c}\text { Primary colour } \\
\text { concentration } \\
(\mathrm{mg} / \mathrm{L})\end{array}$ & $\begin{array}{c}\mathrm{C}_{\mathrm{e}} \\
(\mathrm{mg} / \mathrm{L})\end{array}$ & $\begin{array}{c}\mathrm{q}_{\mathrm{e}} \\
(\mathrm{mg} / \mathrm{g})\end{array}$ & $\begin{array}{c}1 / \mathrm{C}_{\mathrm{e}} \\
(\mathrm{L} / \mathrm{mg})\end{array}$ & $\begin{array}{c}1 / \mathrm{q}_{\mathrm{e}} \\
(\mathrm{g} / \mathrm{mg})\end{array}$ \\
100 & 0.899 & 147.462 & 1.112 & 0.00678 \\
200 & 6.361 & 288.134 & 0.157 & 0.00347 \\
300 & 8.672 & 433.497 & 0.115 & 0.00231 \\
400 & 43.977 & 529.762 & 0.022 & 0.00188 \\
\hline
\end{tabular}

Figure 6. Langmuir isotherm for adsorption of methyl violet by modified palm fiber

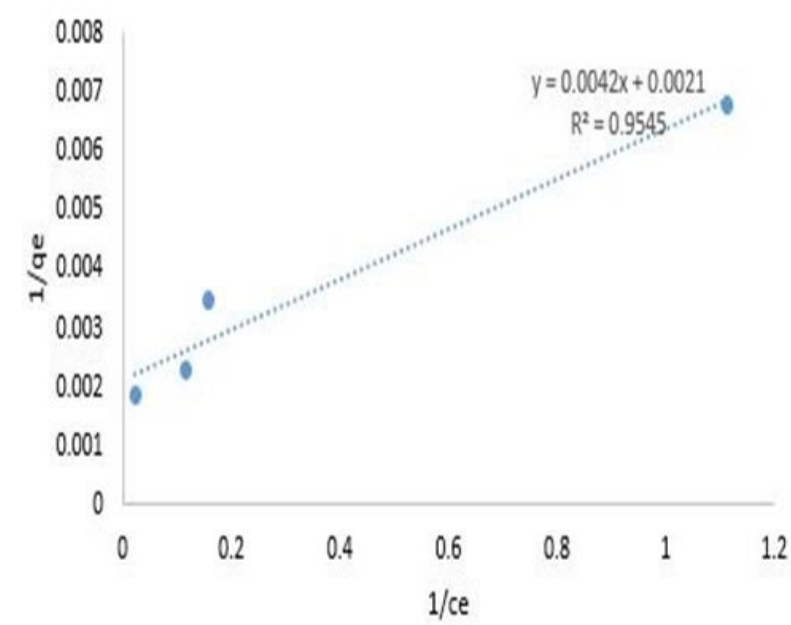

Table 6. Parameters of Langmuir isotherm

\begin{tabular}{ccc}
$\mathrm{q}_{\mathrm{m}}(\mathrm{mg} / \mathrm{g})$ & $\mathrm{K}_{1}(\mathrm{~L} / \mathrm{mg})$ & $\mathrm{R}_{\mathrm{L}}$ \\
476.19 & 0.50 & 0.00990 \\
\hline
\end{tabular}

Table 7. Amounts of $\log C_{e} \log q_{e}$ in the colour of methyl violet for various primary concentrations

\begin{tabular}{ccccc}
$\begin{array}{c}\text { Primary colour concentrations } \\
(\mathrm{mg} / \mathrm{L})\end{array}$ & $\begin{array}{c}\mathrm{C}_{\mathrm{e}} \\
(\mathrm{mg} / \mathrm{L})\end{array}$ & $\begin{array}{c}\mathrm{q}_{\mathrm{e}} \\
(\mathrm{mg} / \mathrm{g})\end{array}$ & $\log \mathrm{C}_{\mathrm{e}}$ & Log $\mathrm{q}_{\mathrm{e}}$ \\
100 & 0.2545 & 9.7455 & -0.59 & 0.99 \\
200 & 0.3760 & 19.6240 & -0.42 & 1.29 \\
300 & 1.7286 & 28.2714 & 0.24 & 1.45 \\
400 & 3.4975 & 36.5025 & 0.54 & 1.56 \\
\hline
\end{tabular}

By calculating the line slope, according to line equation in Figure 7, the amount of $n$ is 2.95. Considering the proper $\mathrm{R}^{2}$ and $\mathrm{n}$, the adsorption of methyl violet dye on modified palm fiber also follows the Freundlich isotherm. The parameters of Freundlich isotherm are shown in Table 8.

$\log q_{e}=\log / k_{f}+1 / n / \log / C_{e}$

Studying the kinetic effects
Pseudo-first-order kinetic model

Pseudo-first-order kinetic equation can be expressed in the following equation (Eq. (7)).

$\log \left(\mathrm{q}_{\mathrm{e}-} \mathrm{q}_{\mathrm{t}}\right)_{=} \log / \mathrm{q}_{\mathrm{e}-}\left(\frac{\mathrm{kt}}{2.303}\right) \mathrm{t}$

$\mathrm{q}_{\mathrm{t}}$ and $\mathrm{q}_{\mathrm{e}}$ are the amount of adsorbed dye in milligrams per gram in each mass unit of adsorbent in time and in equilibrium, and each value is determined using Eq. (8) and (9). 
$\mathrm{q}_{\mathrm{e}}=\left(\mathrm{C}_{0-} \mathrm{C}_{\mathrm{e}}\right) \frac{V}{W}$

$\mathrm{q}_{\mathrm{t}=}\left(\mathrm{C}_{0-} \mathrm{C}_{\mathrm{t}}\right) \frac{V}{W}$

In which, $\mathrm{C}_{\mathrm{t}}$ is the dye concentration in the solution phase according to time $(\mathrm{t})$ pseudofirst-order kinetic model obtained by a linear plot of $\log \left(\mathrm{q}_{\mathrm{e}}-\mathrm{q}_{\mathrm{t}}\right)$ to $\mathrm{t}$. $\mathrm{K}_{1}$ is the rate constant of pseudo-first-order kinetic model according to minutes, and $\mathrm{q}_{\mathrm{e}}$ is the equilibrium adsorption capacity in milligrams per gram obtained from the slope and intercept of Eq. (8). In this study, pseudo-first-order kinetic model was studied for concentrations of 100 ,
200, 300 and 400 milligrams per litter. The results are shown in Figure 8 and Tables 9 and 10. The values of $R^{2}, q_{e}$ and $k_{1}$ are shown in Table 10, where the values of the calculated $\mathrm{q}_{\mathrm{e}}$ and experimental $\mathrm{q}_{\mathrm{e}}$ are not equal, hence the fact that the data do not follow the pseudofirst-order kinetics.

\section{Pseudo-first-order kinetic model}

The linear form of pseudo second order kinetic equation is Eq. (10).

$$
\frac{t}{q_{t}}=\frac{1}{K_{2} q_{e}^{2}}+\frac{1}{q_{e}} t
$$

Figure 7. Langmuir isotherm for adsorption of methyl violet by modified palm fiber

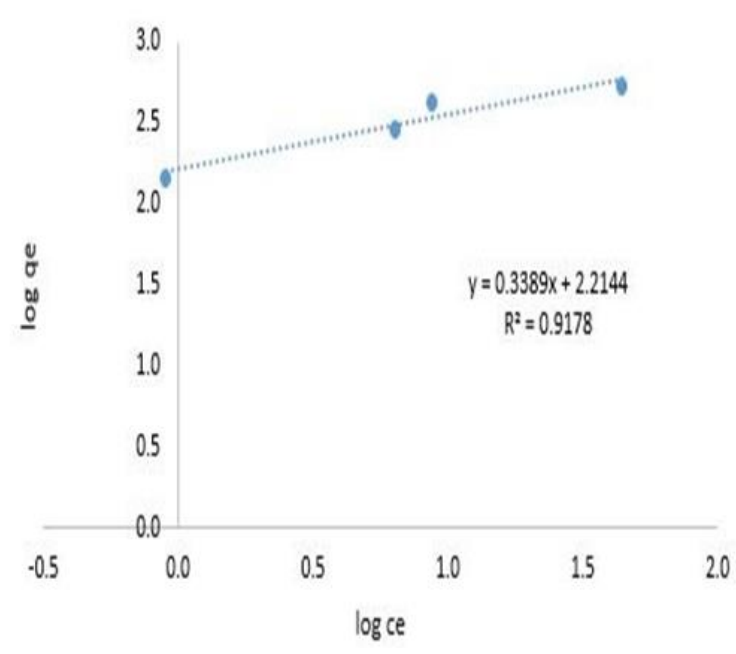

Table 8. Parameters of Langmuir isotherm

\begin{tabular}{cc}
$\mathrm{K}_{\mathrm{f}}(\mathrm{mg} / \mathrm{g})$ & $\mathrm{n}$ \\
163.83 & 2.95 \\
\hline
\end{tabular}

Figure 8. Pseudo-first-order kinetic model

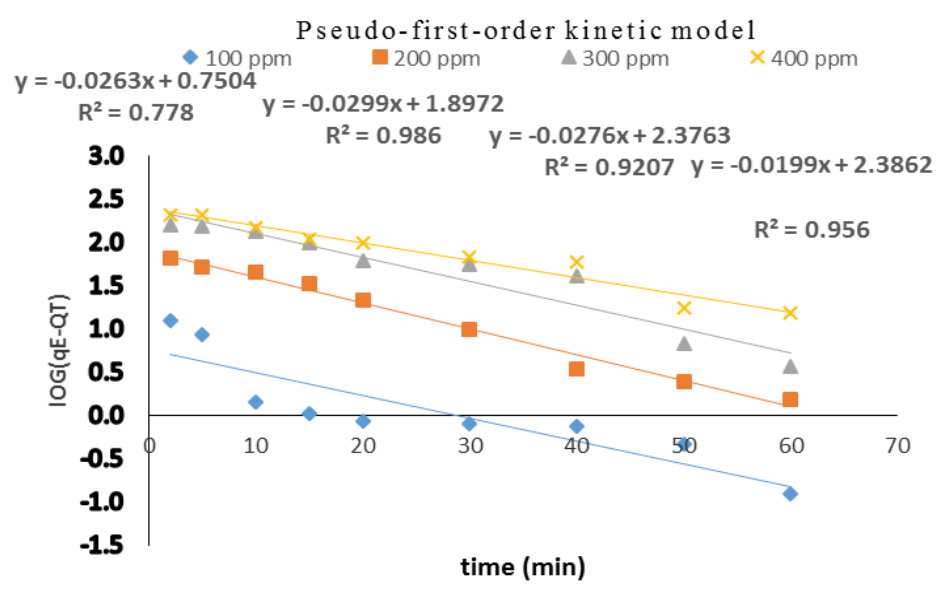


Pseudo-second-order kinetic model was obtained by a linear plot of $t / q_{t}$ to $t$. $K_{2}$ is the rate constant of pseudo-second-order kinetic model according to gram per milligrams in minutes and $\mathrm{q}_{\mathrm{e}}$ is the equilibrium adsorption capacity in milligrams per gram obtained from the slope and intercept of the equation. In this study, pseudo-second-order kinetic model was studied for concentrations of 100, 200,
300 and 400 milligrams per litter. The results are shown in Figure 9 and Tables 11 and 12 . The values of $\mathrm{R}^{2}, \mathrm{q}_{\mathrm{e}}$ and $\mathrm{K}_{2}$ are shown in Table 12 , where the amount of $\mathrm{R}^{2}$ is acceptable and the values of calculated $\mathrm{q}_{\mathrm{e}}$ and experimental $\mathrm{q}_{\mathrm{e}}$ are equal; it can therefore be concluded that the data follow the pseudo-second-order kinetics.

Table 9. Amounts of $\log \left(q_{e}-q_{t}\right)$ for methyl violet removal

\begin{tabular}{ccccc} 
& \multicolumn{4}{c}{$\log \left(\mathrm{q}_{\mathrm{e}}-\mathrm{q}_{\mathrm{t}}\right)$} \\
Time $(\mathrm{min})$ & $100\left(\mathrm{mg} / \mathrm{L}^{-1}\right)$ & $200\left(\mathrm{mg} / \mathrm{L}^{-1}\right)$ & $300\left(\mathrm{mg} / \mathrm{L}^{-1}\right)$ & $400\left(\mathrm{mg} / \mathrm{L}^{-1}\right)$ \\
2 & 1.09 & 1.82 & 2.19 & 2.31 \\
5 & 0.93 & 1.71 & 2.18 & 2.32 \\
10 & 0.15 & 1.65 & 2.12 & 2.16 \\
15 & 0.01 & 1.52 & 1.99 & 2.04 \\
20 & -0.07 & 1.32 & 1.78 & 2.00 \\
30 & -0.10 & 0.99 & 1.74 & 1.82 \\
40 & -0.13 & 0.54 & 1.60 & 1.77 \\
50 & -0.33 & 0.39 & 0.83 & 1.24 \\
60 & -0.91 & 0.19 & 0.57 & 1.18 \\
\hline
\end{tabular}

Table 10. Parameters of pseudo-first-order kinetic model

\begin{tabular}{ccccc}
$\begin{array}{c}\text { Concentration } \\
\left(\mathrm{mg} / \mathrm{L}^{-1}\right)\end{array}$ & $\mathrm{k}_{1}\left(\mathrm{~min}^{-1}\right)$ & $\begin{array}{c}\text { Parameters } \\
\text { Experimental } \\
\mathrm{qe}_{\mathrm{e}}\left(\mathrm{mg} / \mathrm{g}^{-1}\right)\end{array}$ & $\begin{array}{c}\text { Theoretical } \mathrm{q}_{\mathrm{e}} \\
\left(\mathrm{mg} / \mathrm{g}^{-1}\right)\end{array}$ & $\mathrm{R}^{2}$ \\
100 & 0.060 & 147.93 & 5.628 & 0.7780 \\
200 & 0.0688 & 290.60 & 78.922 & 0.9860 \\
300 & 0.0635 & 440.19 & 237.84 & 0.9207 \\
400 & 0.0458 & 547.26 & 243.33 & 0.9565 \\
\hline
\end{tabular}

Figure 9. Pseudo-second-order kinetic model

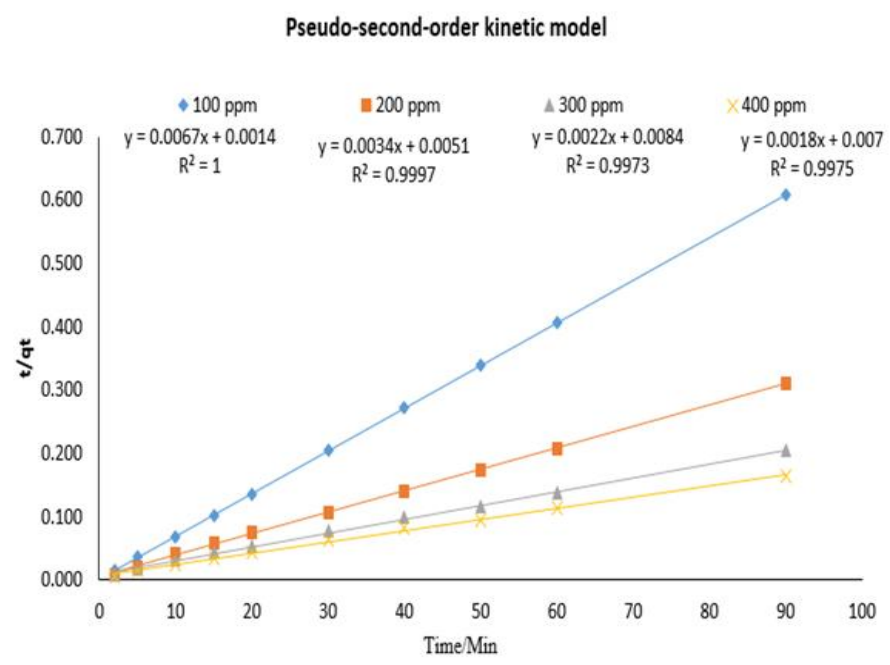


Evaluating real samples

Some real water samples from the tap water, Karun water, Karkheh dam water, and Ramak Company sewage were prepared to evaluate the performance of the method. For this purpose, $25 \mathrm{~mL}$ of each water sample was transferred to $50 \mathrm{~mL}$ shushed balloons and added to $5 \mathrm{~mL}$ of $200 \mathrm{mg} / \mathrm{L}^{-1}$ colour solution, and then, $\mathrm{pH}$ was registered at 9.5 after using suitable amount of $\mathrm{NaOH}$ and bringing to the volume by adding distilled water. Next, each solution was moved to a volumetric flask containing $1.488 \mathrm{~g} / \mathrm{L}^{-1}$ adsorbent and stirred at $120 \mathrm{rpm}$ for $15 \mathrm{~min}$ and cleared by the filter. Then, the adsorption of each solution was determined by spectrophotometry at $\lambda=581.6 \mathrm{~nm}$ and the optimum concentration of colour was calculated. Table 13 shows the removal percent of methyl violet colour for real water and wastewater samples.

Table 11. Amounts of $\mathrm{t} / \mathrm{q}_{\mathrm{t}}$ and time for methyl violet removal

\begin{tabular}{ccccc} 
Time $(\min )$ & $100\left(\mathrm{mg} / \mathrm{L}^{-1}\right)$ & $200\left(\mathrm{mg} / \mathrm{L}^{-1}\right)$ & $300\left(\mathrm{mg} / \mathrm{L}^{-1}\right)$ & $400\left(\mathrm{mg} / \mathrm{L}^{-1}\right)$ \\
2 & 0.015 & 0.009 & 0.007 & 0.006 \\
5 & 0.036 & 0.021 & 0.017 & 0.015 \\
10 & 0.068 & 0.041 & 0.032 & 0.025 \\
15 & 0.102 & 0.058 & 0.044 & 0.034 \\
20 & 0.136 & 0.074 & 0.053 & 0.045 \\
30 & 0.204 & 0.107 & 0.078 & 0.062 \\
40 & 0.272 & 0.139 & 0.100 & 0.082 \\
50 & 0.339 & 0.174 & 0.115 & 0.094 \\
60 & 0.406 & 0.208 & 0.137 & 0.113 \\
90 & 0.608 & 0.310 & 0.204 & 0.164 \\
\hline
\end{tabular}

Table 12. Parameters of pseudo-second-order kinetic model

\begin{tabular}{ccccc}
$\begin{array}{c}\text { Concentration } \\
\left(\mathrm{mgL}^{-1}\right)\end{array}$ & $\mathrm{k}_{1}\left(\mathrm{~min}^{-1}\right)$ & $\begin{array}{c}\text { Parameters } \\
\text { Experimental } \\
\mathrm{qe}_{\mathrm{e}}\left(\mathrm{mg} / \mathrm{g}^{-1}\right)\end{array}$ & $\begin{array}{c}\text { Theoretical } \mathrm{q}_{\mathrm{e}} \\
\left(\mathrm{mg} / \mathrm{g}^{-1}\right)\end{array}$ & $\mathrm{R}^{2}$ \\
100 & 0.0321 & 147.93 & 149.253 & 1.000 \\
200 & 0.0023 & 290.60 & 294.117 & 0.9997 \\
300 & 0.0006 & 440.19 & 454.545 & 0.9973 \\
400 & 0.0005 & 547.26 & 555.55 & 0.9975 \\
\hline
\end{tabular}

Table 13. Removal percent of methyl violet colour in real samples

\begin{tabular}{cccc} 
Sample & $\begin{array}{c}\text { Adding colour } \\
(\mathrm{mg} / \mathrm{L})\end{array}$ & $\begin{array}{c}\text { Remaining colour } \\
(\mathrm{mg} / \mathrm{L})\end{array}$ & $\begin{array}{c}\text { Removal } \\
(\%)\end{array}$ \\
Reference solution & 200 & 7.12 & 96.44 \\
Tap water & 200 & 6.68 & 96.66 \\
Karkhe river water & 200 & 7.33 & 96.33 \\
Karoon river water & 200 & 7.20 & 96.40 \\
Ramak Company & 200 & 8.86 & 95.57 \\
sewage & & & \\
\hline
\end{tabular}




\section{Conclusion}

The adsorption of methyl violet dye was successfully carried out using modified palm fiber. The capability of methyl violet colour output was studied at different experimental conditions and after that, the data of the experiments were analyzed in optimal conditions by Langmuir and Freundlich isotherms, at concentrations of 400-100 ppm and temperature of $25^{\circ} \mathrm{C}$. The performance of two models was evaluated by statistical parameters and the results showed that the pseudo second-order model has been supported. Kinetically, the adsorption capacity is depending with concentration of methyl violet dye in solution and amount palm fiber. In this kind of adsorption, the chemical reaction seems significant in the rate-controlling step and the pseudo-second order chemical reaction kinetics provide the best correlation of the experimental data and the adsorption's mechanism is chemically rate controlling and because of this it is called chemisorption. In this mechanism, the kinetics of sorption should correspond to a reversible second order. In this study, the functional group of palm fiber and methyl blue violet might be taken part in the chemisorption.

\section{Acknowledgment}

The authors gratefully acknowledge the support of this work by the Khouzestan Science and Research Branch, Islamic Azad University, all stuff and laboratory assistants, for their support and cooperation. We also like to thank the stuff of the Analytical Laboratory for their valuable assistance during the course of our study.

\section{Disclosure statement}

No potential conflict of interest was reported by the authors.

\section{References}

[1] M. Smelcerovic, D. Dorđevic, M. Novakovic, M. Mizdrakovic, J. Serb. Chem. Soc., 2010, 75, 855-872.

[2] S. Kim, Y.G. Lee, D.W. Jerng, Int. J. Heat Mass Transfer., 2015, 83, 545-551.

[3] P. Sharma, B.K. Saikia, M.R. Das, Colloids Surf., A., 2014, 457, 125-133.

[4] H. Kim, S.O. Kang, S. Park, H.S. Park, J. Ind. Eng. Chem., 2015, 21, 1191-1196.

[5] N. Daneshvar, V. Vatanpour, A.R. Khataee, M.H. Rasoulifard, M. Rastegar, J. Color Sci. Technol., 2008, 1, 83-89.

[6] S. Chatterjee, S. Chatterjee, B.P. Chatterjee, A.R. Das, A. Guha, J. Coll. Interface Sci., 2005, 228, 30-35.

[7] R.C. Bansal, M. Goyal, Activated Carbon Adsorption. Teylor \& Francis Group Boca Raton Publishing, New York, 2005, Chapter 2, 125-127.

[8] B. Shi, G. Li, G. Wang, C. Feng, H. Tang, J. Hazard. Mater., 2007, 143, 567-574.

[9] L. Wang, A.Q. Wang, J. Chem. Technol. Biotechnol., 2007, 82, 711-720.

[10] M. Morita, T. Kamidate, R. Ito, H. Watanabe, Text. Res. J., 1996, 66, 470-473.

[11] S.A. Avlonitis, I. Poulios, D. Sotiriou, M. Pappas, K. Moutesidis, Desalination., 2008, 221, 259-267.

[12] Y. Fu, T. Viraraghavan, Bioresour. Technol., 2001, 79, 251-262.

[13] K.O. Iwuozor, Adv. J. Chem. Section A., 2019, 2, 105-127.

[14] M. Jafari, Adv. J. Chem. Section A., 2019, 2, 203-215.

[15] G. Mckay, J.F. Porter, G.R. Prased, Water, Air, Soil Pollut., 1999, 114, 423-438.

[16] A.A. Adeyemo, I.O. Adeoye, O.S. Bello, Appl. Water Sci., 2017, 7, 543-568.

[17] A. Ahmad, S. Syafiie, A.H. Wan, S.O. Boon, J. Teknologi., 2002, 36, 31-44.

[18] S.J. Allen, B. Koumanova, J. Univ. Chem. Technol. Metall., 2005, 40, 175-192.

[19] P.K. Malik, Dyes Pigm, 2003, 56, 239-249. 
[20] R.L. Tseng, F.C. Wu, R.S. Juang, J. Surf. Sci. Technol., 2003, 41, 487-495.

[21] S. Karaca, A. Gürses, R. Bayrak, Energy Convers. Manage., 2003, 45, 1693-1704.

[22] C. Namasivayam, M. Dinesh Kumar, K. Selvi, R. Begum Ashruffunissa, T. Vanathi, R.T. Yamuna, Biomass Bioenergy., 2001, 21, 477-483.

[23] K. Nakagawa, A. Namba, S.R. Mukaie, H. Tamon, P. Ariyadej Wanich, W. Tanthapanichakn, Water Res., 2004, 38, 1791-1798.

[24] K. Okada, N. Yamamoto, Y. Kameshima, A. Yasumori, J. Coll. Interface Sci., 2003, 262, 194-199.

[25] V.K. Garg, R. Gupta, A.B. Yadav, R. Kumar, Bioresour. Technol., 2003, 89, 121-124.

[26] M. Ozacar, I.A. Sengil, Bioresour. Technol., 2005, 96, 791-795.

[27] H.S. Samiksha, S. Roohi, Int. J. Environ. Sci., 2013, 3, 1711-1725.

[28] A.E. Ofojama, J. Chem. Eng., 2008, 143, 8595.
[29] A. Mittal, V. Gajba, J. Mittal, J. Hazard. Mater., 2008, 150, 364-375.

[30] Z.Z. Chowdhury, M. Zainsh, R.A. Khan, A.A. Ahmaed, J. Appl. Sci., 2011, 8, 230-237.

[31] S. Kathiresan, M. Vinoth, H.Y. Lim, R. Xavier, K. Marimuthu, S. Sreeamanan, H.M.H. Mas Resemal, Int. J. ChemTech Res., 2010, 2, 1892-1900.

[32] M.H. Isa, S.R.M. Kutty, M.K. Chen, Ammonia nitrigen removal by zeolit and treated oil palm fibre. In: Asia Water 2008 Conference, The Malaysian Water Association, Kuala Lumpur, Malaysia., 2008, 315-327.

[33] E. Daneshvar, M. Kousha, H. Dopeikar, D. Taghavi, A. Bhatnagar, Chem. Eng. J., 2012, 179, 158-168.

[34] F. Heshmatnzhad, M. Pakizeh, M. Esfandyari, F. Heshmatnezhad, A.M. Maskooki, J. Hazard. Mater., 2012, 192, 585-592.

[35] S. Moradi, S. Azizian, J. Mol. Liq., 2016, 219, 909-913.

How to cite this manuscript: Maryam Abrishamkar, Rashin Andayesh, Hossein Hodaee, Optimization of Important Factors on the Adsorption of Methyl Violet by Modified Palm Fiber Using Experimental Design Method, Adv. J. Chem. A, 2020, 3(3), 237-254. 